\title{
Insuficiência de leitos de UTI: crise do capital e mercantilização da saúde
}

\author{
Lack of ICU beds: capital crisis and the commodification of health
}

\section{Rodrigo de Souza MEDEIROS*}

\begin{abstract}
Resumo: Este artigo problematiza a relação entre a insuficiência do número de leitos de Unidades de Terapia Intensiva (UTI) com o movimento de mercantilização da saúde no contexto de desenvolvimento do SUS. Constitui uma pesquisa bibliográfica e documental de natureza quanti-qualitativa, na qual destacamos os dados sistematizados pelo CFM acerca dos leitos de UTI no Brasil, bem como pesquisas sobre a relação entre crise da saúde, crise do capital e mercantilização da saúde. Conclui-se que por envolver alta densidade tecnológica, pessoal especializado e serem serviços de alto custo com reduzida margem de lucro, o setor privado não tem interesse em ampliar leitos de UTI, de forma que tanto no SUS quanto no sistema suplementar de saúde há insuficiência de leitos de UTI determinada por interesses mercantilistas que hegemonizam as relações entre capital e saúde no Brasil.
\end{abstract}

Palavras chaves: Capitalismo. Mercantilização. Saúde. SUS. Sistema Suplementar.

\begin{abstract}
This article questions the relationship between the lack of beds in intensive care units (ICU) and the movement toward health commodification in the context of development of SUS (Single Health System). It constitutes quantitative and qualitative bibliographical and documentary research in which we highlight the systematized data of CFM about ICU beds in Brazil, as well as research on the relationship between health crisis, the crisis of the capital and the commodification of health. It concludes that with high density use of technology, specialized personnel and high-cost services with reduced profit margins, the private sector has no interest in extending ICU beds, so that both within SUS and in the supplementary system there are insufficient ICU beds and this is being determined by market interests that hegemonize relations between capital and health in Brazil.
\end{abstract}

Keywords: Capitalism. Commodification. Health. SUS. Supplementary system.

Submetido em: 29/12/2017. Aceito em: 7/2/2018.

\section{INTRODUÇÃO}

A

presente pesquisa aborda a questão da insuficiência de leitos nas Unidades de Terapia Intensiva (UTI), partindo da premissa que tal fenômeno constitui um dos principais nós críticos do Sistema Único de Saúde (SUS) enquanto expressão de uma das mais complexas problemáticas que afeta tanto o SUS quanto o Sistema de Saúde Suplementar (SSS), atingindo ambos sistemas de saúde em todo território nacional, traduzindo-se em uma visível e contundente falta de acesso à leitos de UTI, afetando a maioria da população do país.

\footnotetext{
* Assistente social. Especialista em atenção à saúde da criança. Trabalha na Diretoria de Atenção à Saúde do Servidor (PROGESP/UFRN, Natal, Brasil). Av. Hermes da Fonseca, s/n, Museu Câmara CA, Natal (RN), CEP.: 59084-100. E-mail: <rodrigosouza_spfc@hotmail.com>. ORC ID: <https://orcid.org/oooo-ooo24307-1701>.
} 
De forma genérica, a insuficiência de leitos de UTI em si é um tema que requer atenção de gestores, trabalhadores em saúde, usuários e pesquisadores. Porém, o que nos chamou a atenção foi o fato de que em meio a uma reconhecida e dramática insuficiência de leitos, se faça acompanhar de uma progressiva diminuição e fechamento de tais leitos, aprofundando o déficit e aumentando a denominada demanda reprimida, resultando em óbitos de usuários dos serviços de saúde, que a rigor poderiam ser evitados, como também, aumentado as situações de judicialização dessa demanda. De acordo com Mapelli Junior (2015), em grande parcela dos casos, o Poder Judiciário, não está preparado para a questão da judicialização da saúde, pois geralmente as demandas são reconhecidas apenas pelos direitos individuais e desconsideram uma análise ampliada das políticas sociais.

Esse quadro denominado de crise do atendimento intensivista requer ser questionado e problematizado na perspectiva de procedermos uma análise para além da aparência deste fenômeno. Nesse sentido, nos deparamos com o desafio de buscar elucidar os principais problemas que determinam a insuficiência de leitos de UTI, problematizando os aspectos que envolvem a oferta de leitos de UTI.

Para tanto, nos utilizamos da pesquisa documental e bibliográfica, destacando-se o levantamento de dados realizado em 2015, pelo Conselho Federal de Medicina (CFM), os quais contém informações do Cadastro Nacional de Estabelecimentos de Saúde (CNES) Agência Nacional de Saúde Suplementar (ANS) e Instituto Brasileiro de Geografia e Estatística (IBGE), buscamos estabelecer as conexões entre a realidade nacional articulada com a atual crise estrutural do capital e seus rebatimentos no SUS no Brasil.

\section{UMA BREVE CONSIDERAÇÃO ACERCA DA OFERTA DE LEITOS DE UTI NO BRASIL}

A insuficiência de leitos de UTI abrange a indisponibilidade desse serviço para a população de modo geral, tanto a UTI pediátrica, UTI neonatal como a denominada UTI adulto, são atendimentos de alta complexidade de difícil acesso aos usuários dos serviços de saúde, independente do atendimento a ser realizado pela rede pública ou privada.

No Brasil, as UTI estão regulamentadas pela portaria no 3.432, de 12 de agosto de 1998 (BRASIL, 1998a), normativa que estabelece critérios de classificação para as Unidades de Tratamento Intensivo (UTI). De acordo com as disposições gerais do referido dispositivo no seu item 1.2, as UTI:

São unidades hospitalares destinadas ao atendimento de pacientes graves ou de risco que dispõem de assistência médica e de enfermagem ininterruptas, com equipamentos específicos próprios, recursos humanos especializados e que tenham acesso a outras tecnologias destinadas a diagnósticos e terapêutica (BRASIL, 1998a, não paginado).

De fato, constata-se que essas unidades requerem alta densidade tecnológica, combinando a utilização de insumos, medicamentos e equipamentos provenientes das indústrias farmacêuticas e de equipamentos médicos, necessidade de incorporação de mão-de-obra cada vez mais especializada, conformando uma interconexão entre capitais que mobilizam e consomem mais de $70 \%$ do conjunto dos gastos público e privado, alimentando uma lógica de produção de serviços centrados nos procedimentos de alto custo.

Argum., Vitória, v. 10, n. 1, p. 229-240, jan./abr. 2018. 
Considere-se que a Portaria no 3.432, de 12 de agosto de 1998 em seu "Art. $2^{\circ}$ - que tratadas finalidades desta Portaria, as Unidades de Tratamento Intensivo serão classificadas em tipo I, II e III" (BRASIL, 1998a, não paginado).

Observe-se que essa classificação em ordem crescente, conforme dispõe a referida Portaria, refere-se ao ordenamento dos níveis de complexidade, sendo maior a de tipo III. Essas unidades também estão estruturadas para atenderem grupos etários e especialidades clínicas específicas, as quais sejam:

\footnotetext{
Neonatal - atendem pacientes de o a 28 dias;

Pediátrico - atendem pacientes de 28 dias a 14 ou 18 anos de acordo com as rotinas hospitalares internas;

Adulto - atendem pacientes maiores de 14 ou 18 anos de acordo com as rotinas hospitalares internas;

Especializada - voltada para pacientes atendidos por determinada especialidade ou pertencentes a grupo específico de doenças (BRASIL, 1998a, não paginado).
}

Pode-se afirmar que em todos os tipos de UTI, há demanda reprimida por leitos, seja tipo I, II ou III; leitos do SUS ou leitos do Sistema Suplementar, requerendo profundas análises e reflexões. Entretanto, no cotidiano do SUS, cada vez mais tem ficado patente as dificuldades tanto do SUS, enquanto sistema público em suas relações com a rede privada que atuam em caráter contratualizado, quanto no próprio Sistema Suplementar cujos contratos se dão através dos planos de saúde. A termo, há dificuldades de oferta de serviços de saúde, quer seja acesso a urgência e emergência, clínica médica, atendimento ambulatorial e exacerbando-se quando se trata de leitos de UTI. Situação essa que nos leva a indagar, quais as reais dificuldades vivenciadas pela população que necessita de leitos de UTI? Quais os principais determinantes dessa situação na realidade de Brasil?

Abordar a problemática das UTIs também requer contextualizar no quadro geral que envolve a definição, conformação e os parâmetros de estruturação dos leitos hospitalares no Brasil, os quais, na atualidade, a rigor deveriam estar organizados com base nos parâmetros definidos pela Portaria Ministerial no 1.101, de 12 de junho de 2002, a qual no seu tópico 3.5 NECESSIDADE DE LEITOS HOSPITALARES caracteriza que: “[...] a) Leitos Hospitalares Totais $>2,5$ a 3 leitos para cada 1.000 habitantes; b) Leitos de UTI: calcula-se, em média, a necessidade de $4 \%$ a 10\% do total de Leitos Hospitalares; (média para municípios grandes, regiões, etc.)” (BRASIL, 2002, p. 17).

Portanto, se houver déficit em termos de leitos hospitalares, provavelmente representa impactos em termos de leitos de UTI. A esse fato, acrescente-se que a demora para conseguir um leito hospitalar, pode representar o agravamento de um paciente e levar a necessidade de um leito de UTI, que por sua vez o acesso é dificultado.

De acordo com esse parâmetro, o número ideal para atender a população que acessa os serviços de Terapia Intensiva, sejam aqueles usuários do SUS ou dos planos e seguradoras de saúde é de 3 leitos de UTI para cada 10.000 habitantes/beneficiários. Considerando a referida portaria como indicador de avaliação, o CFM realizou em 2015 um levantamento situacional sobre os leitos de UTI no Brasil (adulto, infantil, neonatal e especializados). Dentre as in-

Argum., Vitória, v. 10, n. 1, p. 229-240, jan./abr. 2018. 
formações colhidas nessa investigação, podemos enfatizar alguns aspectos que caracterizam a distribuição dos leitos de UTI no Brasil na contemporaneidade.

Tabela 1: Leitos de UTI no Brasil por regiões Administrativas - Leitos SUS

\begin{tabular}{|l|c|c|c|c|}
\hline Região & População* & $\begin{array}{c}\text { Leitos de UTI } \\
\text { SUS** }\end{array}$ & $\begin{array}{c}\text { Leitos de UTI** } \\
\text { /Proporção de } \\
\text { leitos SUS (\%) }\end{array}$ & $\begin{array}{c}\text { Leitos de UTI } \\
\text { SUS/1o.ooo habitan- } \\
\text { tes }\end{array}$ \\
\hline Região Norte & 17.472 .636 & 1141 & $5,7 \%$ & 0,65 \\
\hline Região Nordeste & 56.560 .081 & 4388 & $21,8 \%$ & 0,78 \\
\hline Região Sudeste & 85.745 .520 & 9486 & $47,0 \%$ & 1,11 \\
\hline Região Sul & 29.230 .180 & 3722 & $18,5 \%$ & 1,27 \\
\hline $\begin{array}{l}\text { Região Centro- } \\
\text { Oeste }\end{array}$ & 15.442 .232 & 1436 & $7,1 \%$ & 0,93 \\
\hline Total & 204.450 .649 & 20.173 & $100 \%$ & 0,99 \\
\hline
\end{tabular}

Fontes: *IBGE - Estimativa populacional 2015; **Indicadores obtidos junto ao Cadastro Nacional dos Estabelecimentos de Saúde do Brasil (CNES), do Ministério da Saúde - Competência dez/2015. Elaboração: Conselho Federal de Medicina (2015).

De acordo com a tabela apresentada, a região com o maior número populacional, Sudeste, apresenta mais leitos de UTI, no entanto, a proporção leitos de UTI SUS/10.ooo habitantes apresenta o valor de 1,11; resultado bem discrepante do recomendado pelo Ministério da Saúde, assim como, os índices apresentados em todas as regiões. A situação mais alarmante é na região Norte, a qual apresenta população maior do que a região Centro-Oeste, todavia, a oferta de leitos de UTI é inferior e apresenta os piores indicadores do Brasil, mostrando certa desigualdade na atenção de alta complexidade perante as regiões administrativas.

O esboço anterior esteve relacionado aos usuários exclusivos do Sistema Único de Saúde, maior parcela da população brasileira, 71\% (PORTAL BRASIL, 2015). Será que aqueles que usufruem dos planos de saúde são alvos dessa deficiência do número de leitos de UTI?

Tabela 2. Leitos de UTI no Brasil por regiões Administrativas - Leitos não SUS

\begin{tabular}{|l|c|c|c|c|}
\hline Região & $\begin{array}{l}\text { Beneficiários de } \\
\text { planos privados } \\
\text { de saúde* }\end{array}$ & $\begin{array}{l}\text { Leitos de UTI Não } \\
\text { SUS** (privado / } \\
\text { suplementar) }\end{array}$ & $\begin{array}{l}\text { Proporção Leitos } \\
\text { de UTI Não SUS } \\
(\%)\end{array}$ & $\begin{array}{l}\text { Leitos de UTI } \\
\text { Não SUS/10.ooo } \\
\text { Beneficiários }\end{array}$ \\
\hline Região Norte & 1.898 .902 & 917 & $4,41 \%$ & 4,83 \\
\hline Região Nordeste & 6.792 .803 & 2944 & $61,16 \%$ & 4,33 \\
\hline Região Sudeste & 31.207 .973 & 12714 & $10,93 \%$ & 4,07 \\
\hline Região Sul & 7.169 .256 & 2273 & $9,33 \%$ & 3,17 \\
\hline $\begin{array}{l}\text { Região Centro- } \\
\text { Oeste }\end{array}$ & 3.186 .946 & 1939 & & 6,08 \\
\hline Total & 50.255 .880 & 20.787 & $100 \%$ & 4,14 \\
\hline
\end{tabular}

Fontes: *ANS - Competência set/2015; ${ }^{* *}$ Indicadores obtidos junto ao Cadastro Nacional dos Estabelecimentos de Saúde do Brasil (CNES), do Ministério da Saúde - Competência dez/2015. Elaboração: Conselho Federal de Medicina (2015).

A tabela 2, revela que proporcionalmente, no SSS há uma melhor distribuição de leitos de UTI, haja vista que o número total de leitos de UTI não SUS no Brasil é ligeiramente superior do que aos leitos SUS, sendo a demanda por esses leitos maior do que no SSS. Considerese que embora a quantidade de leitos/consumidores com necessidade de acesso que possu- 
em planos privados de saúde, não leva em conta as inúmeras dificuldades que envolve a negação de atendimento em razão de mensalidades atrasadas ou carência a cumprir, que em geral terminam em demandas por transferência para o SUS.

Essa constatação nos leva a ponderar que embora a quantidade de leitos não SUS esteja adequada à margem de leitos/usuários recomendada pelo Ministério da Saúde, em todas as regiões do Brasil, não é correto comparar uma base que acessa de forma restrita, conforme sua capacidade de pagamento, com a imensa população usuária do SUS que pode acessar de forma universal e integral, donde se inclui também os que podem pagar por desembolso direto e através de planos e seguros saúde.

Os notórios problemas de acesso a leitos de UTI vivenciados também pelos que dispõem de planos de saúde, segundo Malta et al. (2005), explicitam "[...] as principais características do modelo de assistência praticado na saúde suplementar assentam-se na fragmentação do cuidado, na ênfase em procedimentos, nas diretrizes biologicistas e interesses de mercado" (MALTA et al., 2005, p. 146).

De fato, o modelo assistencial na saúde suplementar, está pautado na lógica de fragmentação na atenção à saúde, contendo em seu bojo a lógica da atenção gerenciada, sendo seus atores os planos de saúde, prestadoras de serviços e usuários, cujo controle administrativo está sob os grandes organismos privados, sendo eles os intermediadores entre os produtores dos serviços e consumidores, em que as necessidades dos usuários acabam sendo cooptadas pelas do capital financeiro. Com isso, temos na saúde suplementar, certa deficiência da rede de serviços (insuficiência do apoio diagnóstico terapêutico), inexistência de ofertas específicas (alta complexidade, exames não cobertos, carências) (MALTA et al., 2005).

Os estudos de Nishijima; Cyrillo e Biasoto Jr. (2010), revelam que apesar do setor privado possuir maior infraestrutura em relação ao setor público em procedimentos de diagnose, ele não apresenta estrutura suficiente para atendimentos de demandas de alta complexidade, em que o custo seja elevado como por exemplo leitos de UTI, sendo os beneficiários dos planos e seguradas de saúde encaminhados para estabelecimentos do serviço público, ocasião em que os usuários do plano privado tendem a chegar antes à fila do tratamento público de internação, através da obtenção mais rápida do seu diagnóstico, situação em que os beneficiários ocupam os poucos leitos disponíveis para a população, principalmente aos usuários exclusivos do SUS.

Essa situação, equivocadamente levou a um debate cujos fundamentos atentam contra o princípio da universalidade ao preconizar o ressarcimento do setor privado ao setor público, conforme determina a Lei no 9.656, de 3 de junho de 1998 (BRASIL, 1998b), que regulamenta os planos e seguros privados de assistência à saúde.

A $7^{\text {a }}$ Conferência Municipal de Saúde do Natal (RN), realizada em 2015 (CONSELHO MUNICIPAL DE SAÚDE, 2015), deliberou que ao comprovar que o plano privado não assegurou atendimento, o ressarcimento deve ser feito ao usuário, haja vista que além de ter direito a acesso universal mesmo pagando plano privado, teve seus direitos duplamente violados. Por essa razão, deve ser ressarcido. Em outros termos, o ressarcimento ao SUS além do risco de

Argum., Vitória, v. 10, n. 1, p. 229-240, jan./abr. 2018. 
estimular a busca ativa e a priorização de casos com a finalidade de captação de recursos, em princípio, significa desconhecer o dever do Estado.

Ressalte-se que a estruturação de leitos de UTI requer altos investimentos em infraestrutura, tanto no aspecto de equipamentos como de pessoal especializado, elevando seu custo de manutenção. Cenário que se constata a não rentabilidade de uma ampla oferta desses leitos para grande parte de beneficiários dos planos de saúde, visto seu elevado custo e consequentemente baixo rendimento monetário, assim, ofertando o mínimo possível desse serviço especializado, visto que a saúde privada está sob a égide do capital financeiro. Como exemplo, podemos elucidar que "[...] as intervenções cirúrgicas mais sofisticadas (transplantes, colocação de próteses, cirurgias cardíacas etc.) e os tratamentos mais caros e prolongados (HIV, câncer etc.) acabam atendidos pelo SUS” (INSTITUTO BRASILEIRO DE DEFESA DO CONSUMIDOR, 2007, p. 2). Em suma, revela que o SUS de fato é que assegura o acesso dos serviços de alto custo.

\section{CRISE DO CAPITAL E MERCANTILIZAÇÃO DA SAÚDE: REBATIMENTOS NA INSU- FICIÊNCIA DOS LEITOS DE UTI}

Compreender como as Políticas Sociais estão incorporadas, requer apreender que estamos imersos, segundo Mészáros (2002) em uma crise estrutural do sistema capitalista, que na contemporaneidade, assola a população em escala global.

$\mathrm{Na}$ contemporaneidade, estamos sob a égide do capital financeiro, portador de juros, em que o processo de financeirização está totalmente associado às crises e estratégias do capital em manter suas estruturas. "Principalmente, a partir dos anos 1980, percebe-se o ressurgimento do capital produtor de juros, de forma duradoura, e ele passa a determinar as relações econômicas e sociais do capitalismo contemporâneo" (MENDES, 2015, p. 14).

Essa crise do capital está associada ao esgotamento do sistema capitalista e consequentemente, às suas necessidades estratégicas de acumular riquezas, que são produzidas de maneira coletiva e apropriadas sob o âmbito privado. Essa contradição fundante do capitalismo está ainda mais acentuada na contemporaneidade, através dos vários mecanismos do capital em preservar sua hegemonia, que concomitantemente aumenta cada vez mais as desigualdades que lhe é inerente.

Sob as condições de crise estrutural do capital, seus constituintes destrutivos avançam com força extrema, ativando o espectro da incontrolabilidade total numa forma que faz prever a autodestruição, tanto para este sistema reprodutivo social excepcional, em si, como para a humanidade em geral (MEZÁROS, 2002, p. 100).

O sistema capitalista, assim como, em seus vários estágios de desenvolvimento, na atualidade seu desenvolvimento necessita de artifícios para sua manutenção, dentre os quais, conforme análise de Mandel (1985), a pressão geral do controle de todos os elementos do processo produtivo e reprodutivo, que são diretamente exercidos pelo capital ou indiretamente pelo Estado, estão sendo colocados tanto sob mecanismos para evitar que as crises sociais

Argum., Vitória, v. 10, n. 1, p. 229-240, jan./abr. 2018. 
ameacem o sistema vigente, quanto para proporcionar garantias econômicas de valorização e acumulação do capitalismo tardio ${ }^{1}$.

Diante desse contexto, podemos considerar que o Estado está colocado como mediador dos interesses de classe e direcionado para a manutenção do sistema capitalista em tempos de capital financeiro, dentre as intervenções estatais, podemos vislumbrar as políticas sociais. Segundo Mota (2015), o Estado é participante na criação de mecanismos de reprodução da força de trabalho, e como exemplo, podemos citar as medidas de proteção social, dentre as quais, caracterizam-se as políticas sociais.

Atualmente as políticas, inclusive aquelas que compõe o sistema de seguridade social (assistência social, saúde e previdência), estão pautadas no ideário neoliberal2, "[..] que estão aludidas sob a privatização, a focalização e descentralização" (BEHRING; BOSCHETTI, 2006, p. 156, grifos das autoras). Essas são as características fundantes da seguridade social sob a hegemonia neoliberal, as quais tendem à: regressão de direitos trabalhistas e sociais através de variadas estratégias de precarização e insegurança nas relações de trabalho (terceirização, quarterização), segundo Behring e Boschetti (2006) características inerentes ao processo de supercapitalização, em prol dos monopólios financeiros; da privatização explícita ou induzida de setores de utilidade pública, incluindo a saúde, educação e previdência; configurada em um ambiente ideológico individualista, consumista e hedonista ao extremo.

Esse cenário perpassa todo o contexto no qual as políticas sociais estão inseridas, e de forma contundente, a política de saúde, que está sendo atacada pelas medidas de caráter neoliberal, em que a falta de financiamento, o incentivo à iniciativa privada e a utilização de fundo público para fins mercadológicos e lucrativos estão intensificando a agenda de desmonte do SUS, conforme enfatiza Mendes:

Os impactos da crise contemporânea do capitalismo no SUS ocorreram basicamente na financeirização dos recursos públicos e na apropriação do fundo público pelo capital em busca de sua valorização. Isso pode ser percebido pela forte presença do capital portador de juros no orçamento público federal e no Orçamento da Seguridade Social, nos incentivos financeiros públicos concedidos à saúde privada por meio da permissão da abertura do capital estrangeiro para a exploração das ações e serviços de saúde no país e da permanência do mecanismo de renúncia fiscal e, ainda, na adoção de um ajuste fiscal com larga redução para os recursos da saúde (MENDES, 2015, p. 14).

Bravo (2009), ratifica tais análises complementando que são características da política de saúde no Brasil em tempos de contrarreforma do Estado, o que acomete o descumprimento dos dispositivos constitucionais, chamando a atenção para o fato de que a proposta de política de saúde construída na década de 1980, fomentada pelo Movimento de Reforma Sanitária Brasileira (MRSB), tem sido constantemente desconstruída, pois a saúde está sendo veementemente vinculada ao mercado, enfatizando as parcerias com a sociedade civil e respon-

${ }_{1}$ O capitalismo tardio é a fase do processo de desenvolvimento capitalista na contemporaneidade, ver mais em Mandel (1985).

${ }^{2}$ Iamamoto (2008) O Neoliberalismo se materializa no Brasil, a partir de meados dos anos 1990. Em que acontece uma profunda restruturação do aparelho Estatal, que atropelou as normas constitucionais relativas aos direitos sociais, atingindo profundamente a seguridade social.

Argum., Vitória, v. 10, n. 1, p. 229-240, jan./abr. 2018. 
sabilizando-a para assumir os custos do sistema de saúde. Situação que se observa a privatização atuando no livre mercado e por dentro do SUS, sendo aquele fortalecido pelo crescimento do Sistema de Saúde Suplementar, e neste, observamos a ação das Organizações Sociais (OS), consolidando o fundo público, cada vez mais alocado no setor privado.

A expansão do setor privado por dentro do SUS é o que denominamos de privatização. Ela vem se dando de duas formas: através da compra de serviços privados de saúde 'complementares' aos serviços públicos e, mais recentemente, através do repasse da gestão do SUS para entidades privadas e/ou de direito privado, por meio dos denominados novos modelos de gestão (CORREIA; OMENA, 2013, p. 3).

De acordo com Bravo (2009), observamos dois projetos em disputa, na qual o projeto da reforma sanitária, está perdendo o embate para o projeto voltado para o mercado, em que, ao invés da proposta universalista, estamos vivenciando a focalista, que tem em seu escopo a defesa do papel do Estado na saúde para o atendimento dos segmentos mais pobres da população, pois o direcionamento ao desfinanciamento da política de saúde, coloca a perspectiva universalista em cheque.

O projeto de mercado está progressivamente ganhando mais espaço no cenário de crise do capital, o qual necessita de medidas para a manutenção de sua acumulação. Posto esse cenário, observa-se o SUS como um pano de fundo estratégico para o fomento à acumulação capitalista, pois “[...] no contexto do capitalismo contemporâneo o SUS é organizado e operacionalizado sob as formas de organização do trabalho engendradas pelo regime de acumulação integral, ainda que se considere apenas o âmbito público do sistema" (CAMPOS; SOARES; VIANA, 2015, p. 87).

Para esse estudo, é importante observar de que forma os serviços, principalmente os de alta complexidade como os serviços de terapia intensiva, estão organizados no âmbito do SUS, e a maneira em eles estão inseridos na lógica de produção e acumulação capitalista.

Na análise de Guerra e Gonçalves (2014), acerca do atendimento aos serviços de alta complexidade e suas devidas alocações de recursos, constatou-se que o modelo de gestão e organização da produção de bens e serviços de saúde está em processo de transformação para um padrão empresarial, inclusive em casos que a obtenção de lucro não é primordial.

As autoras ainda demonstram a capacidade que a rede de organizações prestadoras de serviços de alta complexidade tem de gerar riqueza, não somente a assistência à saúde. Sendo assim, alocação de recursos a esse nível fundamenta-se em uma lógica de mercado ou capitalista, a qual refere-se a um retrato da oferta e demanda por serviços, como também a rede de hospitais públicos, conveniados ou credenciados ao SUS.

Diante dos fatos, observa-se o direcionamento financeiro e estratégico da política de saúde para os interesses mercadológicos, tanto no SUS como no Sistema Suplementar, principalmente quando se trata de ações e serviços que requerem investimentos tecnológicos de alto custo (leitos de UTI), cujo produtos são fonte de custos e acumulação de riquezas para apropriação dos grandes monopólios produtores de materiais, insumos e medicamentos.

Argum., Vitória, v. 10, n. 1, p. 229-240, jan./abr. 2018. 
Portanto, a crise do sistema de saúde no Brasil revela as determinações e as inflexões macroeconômicas, ou seja, com crise do capital financeiro, que está pautado em medidas de preservação da acumulação e, consequentemente no direcionamento da privatização e mercantilização dos serviços públicos constitucionalmente universais.

\section{CONSIDERAÇÕES FINAIS}

A problemática da insuficiência do número de leitos de UTI é visivelmente percebida não somente nos dados levantados pelo CFM que demonstra a realidade no país, como também, no cotidiano dos estabelecimentos de saúde de atenção terciária, seja no setor público ou privado, em que o ônus fica por conta dos usuários que necessitam deste serviço em específico. Devemos considerar essa insuficiência no bojo do movimento de produção e reprodução das relações sociais engendradas na sociedade capitalista, em que a política de saúde está alocada sob à lógica mercantilista, visto que vivemos uma

[...] complementariedade invertida em que em vez da rede privada ser complementar à pública, tem absorvido cerca de $60 \%$ dos recursos públicos destinados aos procedimentos de alta e média complexidade, através de convênios e contratação de serviços da rede privada pelo SUS (CORREIA; OMENA, 2013, p. 7).

O movimento é de priorização da transferência dos recursos do SUS para os contratos com os prestadores privados resultando no fortalecimento da iniciativa privada, priorização dos procedimentos e serviços mais rentáveis para os organismos privados, não sendo o caso dos leitos de UTI no SUS, seja na rede pública ou privada de saúde.

Por serem de alto custo as UTI não constituem serviços de interesse do setor privado, dessa forma, o sistema público vem se deparando com dificuldades inclusive de contratualizar leitos privados de UTI. Nesse sentido, considerando a essencialidade do direto a saúde, dentre os leitos privados encontram-se os que estão à disposição do SUS mediante contratos, certamente em quantidade inferior ao potencial de contratação do SUS, justamente porque a mercantilização da saúde constitui fator decisivo para a insuficiência dos leitos de UTI haja vista que os serviços de maior retorno financeiro são alvos dos poderosos interesses e ação do capital monopolista.

Não por acaso, o MRSB colocou a estatização progressiva como uma condição estratégica para se contrapor à lógica privatista e, portanto, para assegurar acesso universal, integral e igualitário a todos (as).

Por fim, constata-se que a insuficiência de leitos de UTI está intimamente imbricada com o movimento de crise do capital e seus mecanismos estratégicos de acumulação, assim, rebatendo na maneira de como as políticas sociais estão estruturadas na contemporaneidade, sob o enfoque do mercado em detrimento da viabilização dos direitos socais, como o acesso universal aos serviços de saúde.

Sendo em relação ao SUS ou ao Sistema Suplementar de Saúde, a demanda da população por leitos de UTI, serão dispostas não com relação as suas necessidades, mas sim pela lógica mercantilista.

Argum., Vitória, v. 10, n. 1, p. 229-240, jan./abr. 2018. 
O modelo de gestão que tornou possível a terceirização dos serviços de saúde por meio das Organizações Sociais nasceu sob a justificativa da necessidade de o Estado superar sua suposta ineficiência na prestação de serviços. Assim, a proposta de um novo modelo de gestão foi elaborada em 1995, pelo Ministério da Administração Federal e da (Contra) Reforma do Estado, prometendo melhores resultados e economia dos recursos, com o objetivo de organizar governos menos dispendiosos e submetidos ao equilíbrio fiscal. Esse processo culminou na redefinição do papel do Estado, o qual passou a ser mais concentrado no fomento e na regulação, retirando sua função de prestador direto dos serviços públicos. A isso se denominou Administração Gerencial.

A Administração Gerencial consagrou a contrarreforma do Estado brasileiro, visto que impulsionou a mercantilização dos setores rentáveis do serviço público de interesse coletivo, onde se encontram os serviços e as unidades de saúde. Nessa direção, a implementação do modelo de gestão das OSs na área da saúde tem viabilizado a apropriação privada do fundo público da saúde.

É importante destacar que as resistências da sociedade civil organizada contra o projeto do capital vêm dificultando o repasse integral da gestão do SUS para setores não estatais. As resistências ao processo de privatização da saúde têm se dado mediante conselhos e conferências a nível municipal, estadual e nacional, que deliberaram contra as formas de terceirização na saúde e em defesa do modelo de gestão já consagrado na legislação do SUS.

De forma mais incisiva, as lutas em defesa do SUS vêm se realizando através dos Fóruns de Saúde estaduais, que já somam 20 em todo o Brasil, Fóruns Municipais, que totalizam 17, e a Frente Nacional Contra a Privatização da Saúde, constituída em 2010. A Frente é composta por diversas entidades, movimentos sociais, fóruns de saúde estaduais e municipais, centrais sindicais, sindicatos, partidos políticos e projetos universitários, e tem protagonizado as lutas por uma saúde universal, de qualidade e estatal, por meio de mobilizações, atos políticos em defesa da saúde, produção de artigos e organizações de coletânea, reuniões, seminários, rodas de conversas, articulação junto aos trabalhadores, manifestos, cartas abertas, entre outros documentos que contribuem para desvendar a privatização em curso e convocar a população para a defesa do SUS e para o combate aos modelos de gestão privatizantes.

Tendo em vista que os rumos da política de saúde brasileira estão na contramão da consolidação do arcabouço legal do SUS, bem como do Projeto de Reforma Sanitária, faz-se necessário fortalecer cada vez mais esses espaços organizativos e de lutas em defesa de uma saúde pública e de qualidade. Tais espaços tornam-se cada vez mais importantes para o debate contemporâneo sobre a conquista, a consolidação e a universalização do direito à saúde. Por meio deles, os trabalhadores e usuários da saúde pública poderão compreender os caminhos da política de saúde brasileira, fortalecendo o pensar e o agir coletivo na defesa de uma política de saúde pública, universal e de qualidade, e ressaltando a necessidade de defesa de um novo projeto societário, no qual a vida humana não seja negociada como mercadoria.

\section{REFERÊNCIAS}

BEHRING, E. R; BOSCHETTI, I. Política social: fundamentos e história. 2. ed. São Paulo: Cortez, 2006.

Argum., Vitória, v. 10, n. 1, p. 229-240, jan./abr. 2018. 
BRASIL. Ministério da Saúde. Portaria Ministerial no 1.101, de 12 de junho de 2002. Parâmetros assistenciais do SUS. Brasília (DF), 2002. Disponível em:

<http://www.betim.mg.gov.br/ARQUIVOS_ANEXO/Portaria_1001;;200706o6.pdf>. Acesso em: 2 nov. 2017.

BRASIL. Ministério da Saúde. Portaria no 3.432, de 12 de agosto de 1998. Estabelece critérios de classificação para as Unidades de Tratamento Intensivo - UTI. Brasília (DF), 1998a. Disponível em:

<http://bvsms.saude.gov.br/bvs/saudelegis/gm/1998/prt3432_12_08_1998.html>. Acesso em: 2 nov. 2017.

BRASIL. Presidência da República. Lei no 9.656, de 3 de junho de 1998. Dispõe sobre os planos e seguros privados de assistência à saúde. Brasília (DF), 1998b. Disponível em: <http://www.planalto.gov.br/ccivil_o3/leis/L9656.htm>. Acesso em: 2 nov. 2017.

BRAVO, Maria Inês. Política de Saúde no Brasil. In: MOTA, Ana Elizabete et al. Serviço Social e Saúde: formação e trabalho profissional. 4. ed. São Paulo: Cortez, 2009. p. 88-110.

CAMPOS, Celia Maria Sivalli; VIANA, Nildo; SOARES, Cassia Baldini. Mudanças no capitalismo contemporâneo e seu impacto sobre as políticas estatais: o SUS em debate. Saúde e Sociedade, São Paulo, v. 24, n. 1, p.82-91, jun. 2015.

CONSELHO FEDERAL DE MEDICINA. Medicina Intensiva no Brasil: 2015. Brasília (DF), 2015. Disponível em: <http://portal.cfm.org.br/images/PDF/leitosuti_porregiao.pdf>. Acesso em: 12 nov. 2017.

CONSELHO MUNICIPAL DE SAÚDE (Natal). Relatório Final. In: CONFERÊNCIA MUNICIPAL DE SAÚDE DE NATAL, 7., 2015. Relatório Final... Natal: Secretaria Municipal de Saúde Natal, 2015.

CORREIA, Maria Valéria Costa; OMENA, Valéria Coêlho. A mercantilização da saúde e a política de saúde brasileira: a funcionalidade da saúde suplementar. In: JORNADA INTERNACIONAL DE POLÍTICAS PÚBLICAS, 6., 2013, São Luís. Anais... São Luís: Cidade Universitária da Universidade Federal do Maranhão, 2013. p. 1-9.

GUERRA, Mariana; GONÇALVES, Andréa de Oliveira. A lógica capitalista na alocação de recursos para os serviços de saúde de alta complexidade. Revista Eletrônica Gestão \& Saúde, Brasília (DF), v. 5, n. 3, p.791-795, out. 2014.

IAMAMOTO, M. V. Serviço social em tempo de capital fetiche: capital financeiro, trabalho e questão social. 2. ed. São Paulo: Cortez, 2008.

INSTITUTO BRASILEIRO DE DEFESA DO CONSUMIDOR. Planos de saúde: conheça seus direitos contra abusos e armadilhas, São Paulo, 2007. Disponível em:

<http://www.idec.org.br/uploads/publicacoes/publicacoes/folheto-plano-saude.pdf>.

Acesso em: 1o dez. 2017. 
MALTA, D.C. et al. Modelos assistenciais na saúde suplementar a partir da produção do cuidado. In: MALTA, D. C. et al. (Orgs.). Duas faces da moeda: microrregulação e modelos assistenciais na Saúde Suplementar. Brasília (DF): Ministério da Saúde, 2005.

MANDEL, E. O capitalismo tardio. São Paulo: Nova Cultural, 1985.

MAPELLI JUNIOR, Reynaldo. Judicialização da saúde e políticas públicas: assistência farmacêutica, integralidade e regime jurídico: constitucional do SUS. 2015. $390 \mathrm{f}$. Tese (Doutorado em Ciências)-Programa de Radiologia, Faculdade de Medicina da Universidade de São Paulo, São Paulo, 2015.

MENDES, Àquila. O subfinanciamento e a mercantilização do SUS no contexto do capitalismo contemporâneo em crise. In: BRAVO, Maria Inês Souza et al. A mercantilização da saúde em debate: as organizações sociais no Rio de Janeiro. Rio de Janeiro: UERJ; Rede Sirius, 2015. p. 11-19.

MÉSZÁROS, István. Para além do capital: rumo a uma teoria da transição. São Paulo: Boitempo, 2002.

MOTA, Ana Elizabete. Cultura da crise e seguridade social. 7. ed. São Paulo: Cortez, 2015.

NISHIJIMA, M.; CYRILLO, D.C.; BIASOTO JR. G. Análise econômica da interação entre a infraestrutura da Saúde pública e privada no Brasil. Economia e Sociedade, Campinas, v. 19, n. 3 (40), p. 589-611, dez. 2010. Disponível em:

<http://www.scielo.br/pdf/ecos/vign3/o7.pdf>. Acesso em: 1o dez. 2017.

PORTAL BRASIL. Maioria dos usuários aprovam atendimento no SUS. Brasília (DF), 2015. Disponível em: <http://www.brasil.gov.br/saude/2015/o6/usuarios-aprovamatendimento-do-sus>. Acesso em: 2 nov. 2017.

\section{Rodrigo de Souza MEDEIROS}

Assistente social. Especialista em atenção à saúde da criança. Trabalha na Diretoria de Atenção à Saúde do Servidor. 